\title{
Comparison of Techniques for Tibial Dyschondroplasia Assessment in Broiler Chickens
}

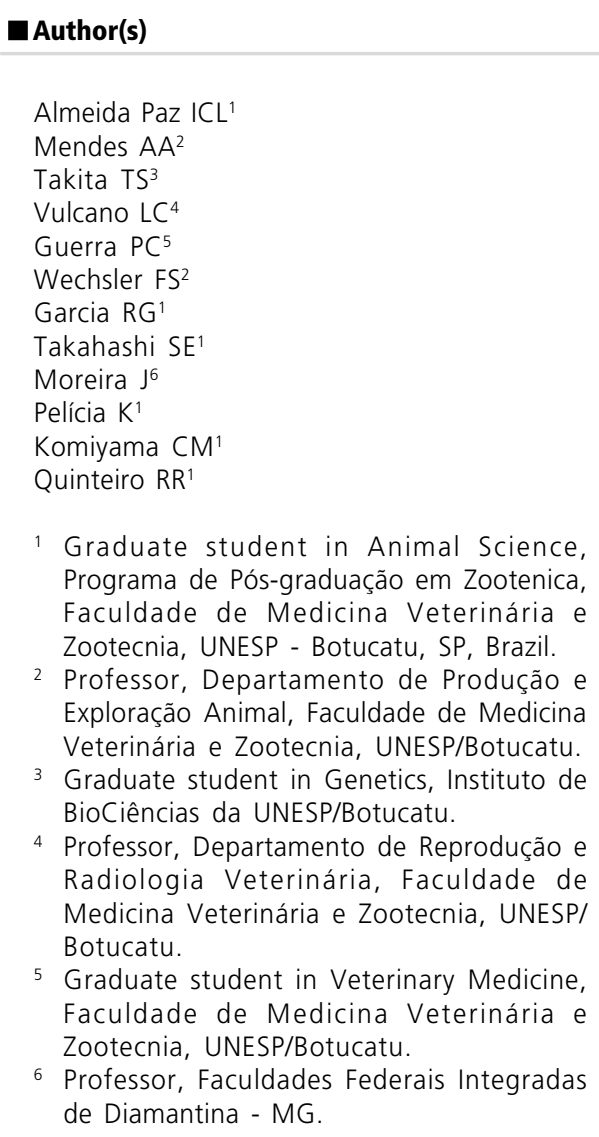

\section{Mail Address}

Ibiara Correia de Lima Almeida Paz

Faculdade de Medicina Veterinária e Zootecnia - UNESP

Fazenda Experimental Lageado, $s / \mathrm{n}^{\circ}$

Departamento de Produção e Exploração Animal

18.618-000. Botucatu, SP, Brasil

E-mail: ibiara@fca.unesp.br arielmendes@fca.unesp.br

\section{Keywords}

histology, lixiscope, macroscopic lesions, optical radiographic densitometry, tibial dyschondroplasia.

\section{ABSTRACT}

This study was carried out at Faculdade de Medicina Veterinária e Zootecnia, Universidade Estadual Paulista, Botucatu, SP, Brazil, with the objective of evaluating the efficacy of four techniques in the assessment of tibial dyschondroplasia lesions in broiler chickens. Four hundred Cobb male chicks were reared from 1 to 39 days of age. At 39 days, forty birds were selected and tibial dyschondroplasia status was assessed by four different techniques: evaluation using the lixiscope, macroscopic examination, histological examination and bone mineral density assessment using optical radiographic densitometry. The efficacy of each technique to assess dyschondroplasia lesions in the tibial growth plate was determined in comparison to histology, which was considered to be $100 \%$ efficient. The correlation results between lixiscope analysis and histology were poor. Macroscopic scores and densitometry readings were highly correlated with histology scores, and it is considered that these techniques reliably reproduce the status of the growth plate.

\section{INTRODUCTION}

Bone marrow calcification in the growth plate is a progressive process associated to chondrocyte maturation. The bone marrow undergoes calcification only after chondrocytes have proliferated, hypertrophied and degenerated. Many events occur on the epiphysis of long bones during such process, with profound morphologic and biochemical changes (Berchieri, 2000). Since the growth rate of the tibia is much faster than the growth rate of other long bones in broiler chickens, a metabolic disease called tibial dyschondroplasia might occur, which is characterized by the presence of an abnormal cartilage mass in the epiphyseal growth plate. This cartilage is the pre-hypertrophic cartilage that did not undergo calcification, because the blood vessels from the metaphysis have not invaded the hypertrophic zone.

There are many techniques that may be used to characterize and assess tibial dyschondroplasia. Most of the reported techniques are based on post-mortem examination, from which macroscopic and histological examination are the most frequently used (Cruickshank \& Sim, 1986; Thorp, 1992; Thorp et al., 1993; Kuhlers \& McDaniel, 1996). Macroscopic examination is the simplest method and consists in visually scoring the dyschondroplastic lesion that is present in the growth plate of the proximal tibial epiphysis. Scores range between 0 (zero) and 3 (three), according to the methodology initially described by Thorp et al. (1997). Nevertheless, macroscopic examination of only one section of affected bones is not the most adequate method to evaluate the incidence and severity of dyschondroplasia, and histology is thus necessary to distinguish between the lesions caused by dyschondroplasia and other diseases that also affect the epiphysis growth plate (Thorp, 1992; Thorp et al., 
1995). The histological examination also permits to evaluate the morphology and distribution of chondrocytes in the tibial growth plate of the birds. Cells responsible for bone growth may show different lesion degrees, ranging from an uneven distribution of chondrocytes to degenerative changes on chondrocyte cytoplasm and nuclei (Orth \& Cook, 1994; Ling et al., 1995; Thorp et al., 1997; Takita, 1998; Gonzales \& Macari, 2000).

Immediate diagnosis of tibial dyschondroplasia is possible in live birds by means of a portable X-ray fluoroscope, with the acronym lixiscope (Bartels et al., 1989; Kestin et al., 1999; Murakami, 2000). This device uses a low-intensity gamma source of 125 ( $27 \mathrm{keV}$ ) to evaluate the affected bone and converts it into electrons and visible-light output image, which is multiplied 45 to 50,000 times and displayed on a screen (Bartels et al., 1989). Although the device is widely used in breeding programs, some studies have reported that it may be effective in detecting severe lesions but do not show the same efficacy when small lesions are present (Thorp, 1997; Takita, 1998). According to Thorp (1997), the lixiscope failed to detect lesions in $47 \%$ of males and $35 \%$ of females.

Dyschondroplasia may be identified in live birds by radiographic examination after the second week of age (Lynch et al., 1992). Therefore, radiographic optical densitometry may be used to evaluate the tibial dyschondroplasia status. Diseases such as osteoporosis and osteochondrosis have been studied in different animal species using bone densitometry, including the technique of radiographic optical density (Louzada et al., 1990; Garton et al., 1994; Louzada, 1997; Jeffcott \& Henson, 1998). On the other hand, few studies have been carried out with broiler chickens.

This study compared techniques for tibial dyschondroplasia assessment in broiler chickens in order to establish their actual efficacy when compared to histology examination, which was considered $100 \%$ efficient.

\section{MATERIAL AND METHODS}

The study was carried out in the poultry facilities at Faculdade de Medicina Veterinária e Zootecnia da UNESP, Campus de Botucatu. Four hundred Cobb male chicks were reared from 1 to 39 days of age according to commercial husbandry practices. Birds were fed water and diet ad libitum throughout the experiment.

At 39 days old, a subsample of 40 birds was selected using a portable low-intensity $\mathrm{X}$-ray imaging device (lixiscope). Birds with dyschondroplastic lesion scores from 0 to 3 were selected and used in the analyses of the present study. Four different techniques used in the diagnosis of tibial dyschondroplasia were evaluated: histological and macroscopic assessment, analysis with the lixiscope, and bone mineral density analysis (optical densitometry of radiographs).

The lixiscope analysis was performed at the poultry house. Birds were identified and the right proximal tibia and distal femur were evaluated. The size of the cartilage in the growth plate was scored from 0 to 3 , based on the methodology previously described by Bartels et al. (1989).

After analysis using the lixiscope, the birds were transferred to the Veterinary Hospital of Faculdade de Medicina Veterinária e Zootecnia, UNESP, Botucatu/ SP. Bone mineral density analysis was performed on radiographs taken from the right femur-tibia articulation. The technique is based on the comparison of the grey levels of the analysed bone with the grey levels of a pre-defined aluminum phantom with known graduate density that is radiographed simultaneously.

All radiographs were taken using $X$-ray films from the same lot number and routine radiological procedures. A green X-ray film was placed in a cassette measuring $18 \times 24 \mathrm{~cm}$ and equipped with rare earth screens. The X-ray device was placed at a focus-tofilm distance of $90 \mathrm{~cm}$ and calibrated for $45 \mathrm{kVp}$ and $3.2 \mathrm{mAs}$. A calibration aluminum wedge was placed onto the cassette, $3.0 \mathrm{~cm}$ distant from the region that would be radiographed and parallel to it, to be used as a densitometry reference standard. The animals were positioned in ventral decubitus and the right leg was stretched onto the cassette Development and fixation of radiographs were carried out in a standard automatic processing apparatus. Radiographic images were scanned and analyses were performed using the software ATHENA-SIA (Leal, 2002).

The region used as standard in the readings was the proliferation plaque in the proximal epiphysis of the right tibia (Figure 1). The readings were performed using the inclination axis of the reading window as zero; the height of the reading window as $10 \mathrm{~mm}$ and the width varied between 40 and $45 \mathrm{~mm}$ according to bone size. Besides, a perfect visualization of the fibula was considered as the horizontal standard for fine adjustments of the reading area. Figure 2 shows the calculation of the radiographic optical density.

The birds were then culled in the Experimental Slaughterhouse of Faculdade de Medicina Veterinária e Zootecnia. Right tibias were sampled for the 
Almeida Paz ICL, Mendes AA, Takita TS, Vulcano LC, Guerra PC, Wescheler FS, Garcia RG, Takahashi SE, Moreira J, Pelícia K, Komiyama CM, Quinteiro RR

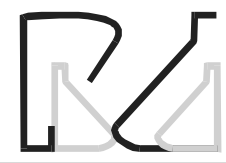

Comparison of Techniques for Tibial Dyschondroplasia Assessment in Broiler Chickens macroscopic and histological examinations. Tibias were dissected and fixed in 10\% buffered formalin for 24 hours.

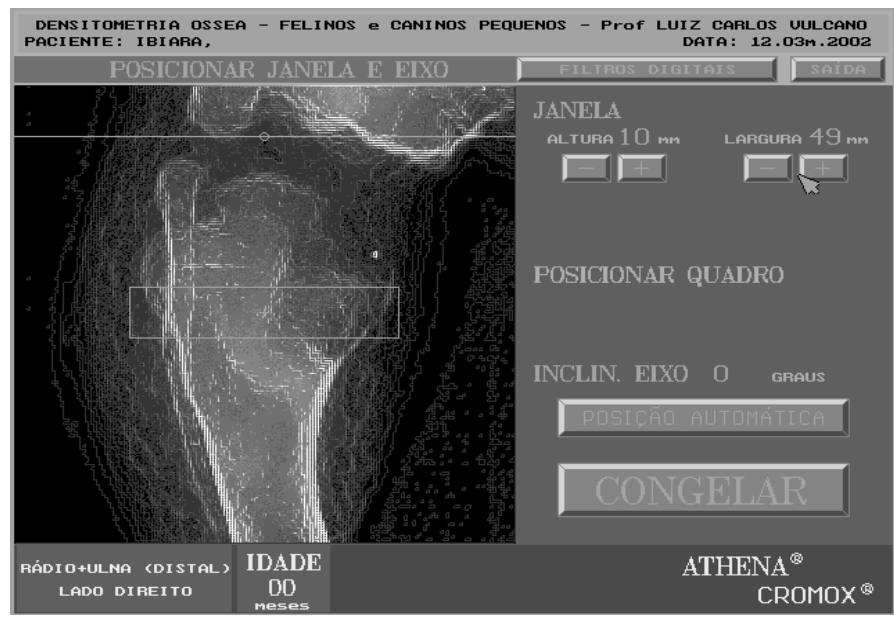

Figure 1 - Standard reading region, axis inclination and reading window size (Software ATHENA - SIA).

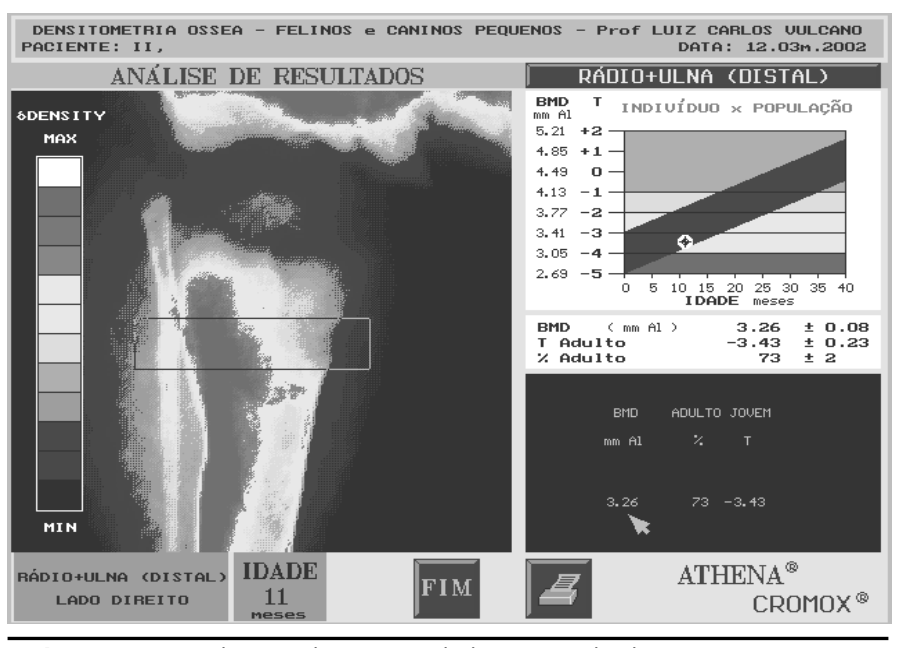

Figure 2 - Radiographic optical density calculation.

Macroscopic evaluation was based on the thickening of the cartilage present in the growth plate of the proximal tibial epiphysis. Longitudinal cuts were performed and the bones were scored according to cartilage thickening (Figure 3 ). Score 0 was given epiphyses without lesions, whereas scores 1 to 3 indicated growth plates with lesions varying from small, moderate and severe, according to the methodology described by Thorp et al. (1997).

The histopathological evaluation of the growth plate is based on the arrangement and integrity of chondrocytes. The tibias were decalcified and embedded in paraffin. Histological cuts (7 ìm) were placed onto glass slides and stained with hematoxylineosin (HE). The growth plate was divided into proliferative zone, prehypertrophic zone and hypertrophic zone, and scored from 0 to 3 according to Takita (1998).

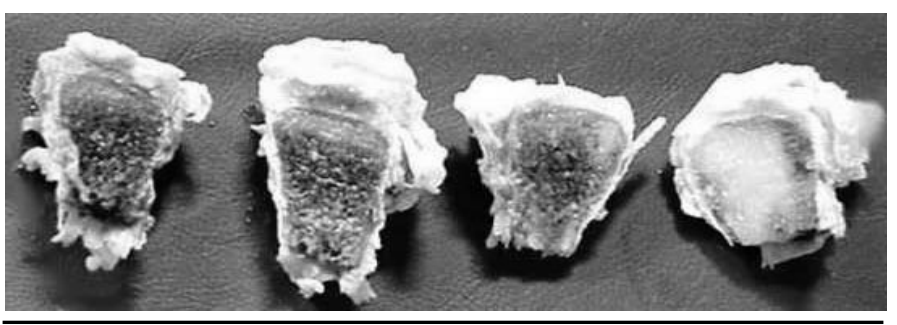

Figure 3 - Macroscopic scores of tibial dyschondroplasia lesions.

Statistical analysis was performed using the software SAEG (1993) at 1\% of probability. Different means were compared by Tukey's test and Spearman's rank correlation coefficients were calculated.

\section{RESULTS AND DISCUSSION}

The total number and percentage of dyschondroplastic lesions in the growth plate identified by histology, macroscopic analysis and the lixiscope evaluation are shown in Table 1, according to lesion score. In each one of the score categories, lixiscope results were significantly different $(p<0.01)$ from histology and macroscopic results. These findings corroborate previous studies (Thorp et al., 1997; Takita, 1998; Murakami, 2000) and evidence that lixiscope analysis has lower efficacy in detecting lesions caused by dyschondroplasia in broilers. Nevertheless, Bartels et al. (1989) reported no differences in the incidence of tibial dyschondroplasia diagnosed using histology or the lixiscope.

Table 2 shows the correlation between the methods used in the present study to assess tibial dyschondroplasia. The histological evaluation had higher correlation with optical densitometry using radiographs, followed by macroscopic examination. Considering the efficacy of histological examination to evaluate growth plate lesions as 100\% (Thorp, 1992; Thorp et al., 1995; Takita, 1998), optical densitometry using radiographs and macroscopic analysis had 95\% and $90 \%$ of efficacy, respectively. The lixiscope showed low correlation with the other techniques, including histological examination. The efficacy of detection of tibial dyschondroplasia lesions in broilers was only $71 \%$ when the lixiscope was used. 


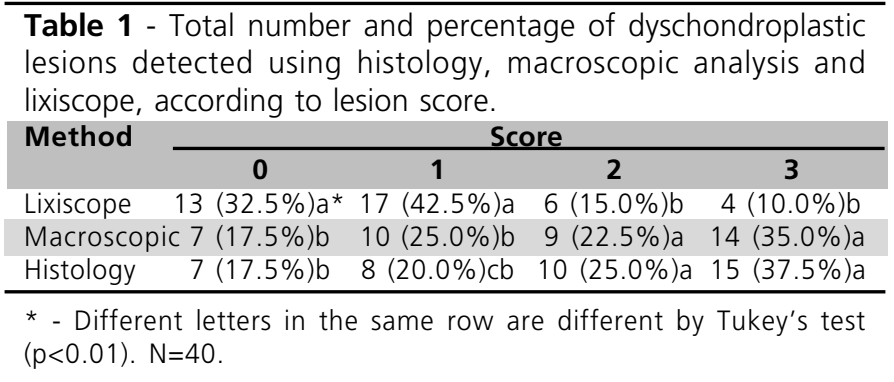

Table 2 - Correlation coefficients between macroscopic analysis, lixiscope evaluation, radiographic optical densitometry (bone mineral density) and histology in the characterization of lesions caused by tibial dyschondroplasia.

\begin{tabular}{lcccc} 
& Histology & Macroscopic & Lixiscope & BMD \\
Histology & 1.00 & & & \\
Macroscopic & 0.90 & 1.00 & & \\
Lixiscope & 0.71 & 0.77 & 1.00 & \\
BMD & 0.95 & 0.83 & 0.72 & 1.00 \\
\hline
\end{tabular}

1 - Bone mineral density. Spearman's rank correlation coefficients $(p<0.01)$ Não há indicação do que o autor quer mostrar e daquilo que é diferente com proabilidade $p<0.01$. Se ele quiser, colocar no título da tabela: "Spearman's rank correlation coefficients between macroscopic analysis..."

\section{CONCLUSIONS}

Optical densitometry using radiographs showed higher efficacy in the diagnosis of dyschondroplastic lesions, followed by macroscopic evaluation.

The lixiscope was less effective in diagnosing lesions, and it failed not only when small lesions were present.

Correlation analysis showed that macroscopic analysis and bone mineral density assessment by optical densitometry using radiographs are able to characterize the status of the growth plate in the proximal epiphysis of the tibia in broiler chickens.

\section{REFERENCES}

Bartels JE, McDaniel GR, Hoerr FJ. Radiographic diagnosis of tibial dyschondroplasia in broilers: a field selection technique. Avian Diseases 1989; 33:254-257.

Berchieri Jr. A. Enfermidades metabólicas em frangos de corte. In: Gonzales E, Macari M. Editores. Doenças das Aves. Campinas: FACTA; 2000. 490p.

Cruickshank J, Sim J. Morphometric and radiographic characterization of tibial bone of broiler chickens with twisted leg disorders. Avian Diseases 1986; 30:699-708.

Garton MJ, Robertson EM, Gilbert FJ et al. Can Radiologists detect osteopenia on plain radiographs? Clinical Radiology 1994; 49:118122.
Gonzales E, Macari M. Enfermidades metalóbicas em frangos de corte. In: Berchieri Jr A, Macari M. Doenças das aves. Campinas: FACTA; 2000. p.451-464.

Jeffcott LB, Henson MD. Studies on growth cartilage in the horse and their application to aetiopathogenesis of dyschondroplasia (osteochondrosis). The Veterinary Journal 1998; 156:177-192.

Kestin SC, Su G, Sorensen, S. Different commercial broiler crossea have different susceptibilities to leg weakness. Poultry Science 1999; 78(8):1085-1090

Kuhlers SDL, McDaniel GR. Estimates of heritabilities and genetic correlations between tibial dyschondroplasia expression and body weight at two ages in broilers. Poultry Science 1996; 75(8):959961.

Leal ACR. Determinação dos valores normais da densidade mineral óssea (DMO) da extremidade distal do rádio em cães por meio da técnica de densitometria óptica em imagens radiográficas: correlação entre o peso, sexo e idade [dissertação]. Botucatu (SP): Universidade Estadual Paulista; 2002.

Ling J, Kincaid SA, McDaniel GR. Ultrastructural changes of chondrocytes of growth plates of young broiler chickens predisposed to tibial dyschondroplasia. Poultry Science 1995; 74:788-794

Louzada MJQ, Xavier CAM, Marques Neto JF. Ação da calcitonina na resolução de perfurações ósseas em coelhos: controle fotodensitométrico e histológico. Revista Brasileira de Reumatologia 1990; 30(4):111-116.

Louzada MJQ. Densidade de peças ósseas de frangos. Estudo pela densitometria óptica radiográfica. Veterinária e Zootecnia 1997; 9:95-109.

Lynch M, Thorp BH, Whitehead CC. Avian tibial dyschondroplasia: a sequential radiological study. Avian Pathology 1992; 21:275285

Murakami AE. Balanço eletrolítico da dieta e sua influência sobre o desenvolvimento dos ossos de frangos. In: Conferência Apinco de Ciência e Tecnologia Avícolas, 2000; Campinas, São Paulo. Brasil. p.33-61.

Orth MW, Cook ME. Avian tibial dyschondroplasia: a morphological and biochemical review of the growth plate lesion and its causes. Veterinary Pathology 1994; 31:403-414.

SAEG. Sistema para análise estatística e genéticas. Manual de utilização do programa SAEG. Viçosa: UFV, 1993. 59p.

Takita TS. Efeito do genótipo, do ambiente e da interação genótipo $x$ ambiente na incidência de discondroplasia tibial em frangos de corte machos [dissertação]. Botucatu (SP): Universidade Estadual Paulista; 1998.

Thorp BH. Abnormalities in the growth of long bones. In: Whitehead CC. Editor. Bone biology and skeletal disorders in poultry. Poultry Science Symposium, 23; 1992; Abindin. Inglaterra. Abingdon: Carfax; 1992. p.147-166. 
Almeida Paz ICL, Mendes AA, Takita TS, Vulcano LC, Guerra PC, Wescheler FS, Garcia RG, Takahashi SE, Moreira J, Pelícia K, Komiyama CM, Quinteiro RR

Thorp BH, Ducro B, Whitehead CC, et al. Avian tibial dyschondroplasia: the interaction of genetic selection and dietary 1,25-dihydroxycholecalciferol. Avian Pathology 1993; 22:311-24.

Thorp BH, Jakowlew SB, Goddard C. Avian tibial dyschondroplasia: local deficiencies in growth factors are integral to the aetiopathogenesis. Avian Pathology 1995; 25:135-48.

Thorp BH, Dick L, Zefferies D, Houston B, et al. An assessment of the efficacy of the lixiscope for the detection of tibial dyschondroplasia. Avian Pathology 1997; 26:97-104. 